\title{
Is primary closure still a reliable technique in carotid endarterectomy?
}

\author{
Aykut Şahin (D), Sadettin Dernek (D) \\ Department of Cardiovascular Surgery, Eskişehir Osmangazi University Faculty of Medicine, Eskişehir, Turkey
}

Received: October 14, 2020 Accepted: October 22, 2020 Published online: November 06, 2020

\section{ABSTRACT}

Objectives: This study aims to evaluate perioperative and long-term results of carotid endarterectomy (CEA) in terms of primary closure and patch techniques.

Patients and methods: This retrospective study included a total of 289 patients (145 males, 144 females; mean age $64.9 \pm 3.85$ years; range, 53 to 84 years) who underwent elective CEA in our clinic between January 2014 and January 2019. The patients were divided into two groups as Group 1 consisting of patients who received patch closure $(n=62)$ and Group 2 consisting of patients who received primary closure $(\mathrm{n}=227)$. Both groups were compared in terms of demographic and clinical data, and postoperative results.

Results: There was no significant difference between the groups in terms of demographic characteristics. The mean cross-clamp time was significantly shorter in Group 2 ( $\mathrm{p}=0.001)$. The rate of hematoma formation was higher in Group 1 ( $\mathrm{p}=0.048)$, while acute myocardial infarction $(p=0.431)$, stroke in the short-term $(p=0.839)$ and long-term $(p=0.429)$, development of restenosis $\geq 70 \%(p=0.839)$, and mortality rates $(\mathrm{p}=1.0)$ did not differ significantly between the groups.

Conclusion: Our study results indicate that the application of patch or primary closure techniques during CEA has no significant superiority to each other in the early- and mid-term. In eligible cases and in whom the arterial diameter is over $5 \mathrm{~mm}$, primary closure can be performed safely.

Keywords: Carotid endarterectomy, hematoma, patch closure, primary closure, restenosis.

Carotid endarterectomy (CEA) reduces the risk of cerebrovascular ischemic events. Additionally, it is effective in preventing recurrent stroke in patients with symptomatic carotid artery stenosis (CAS) and postoperative stroke with a mortality rate below $3 \% .^{[1,2]}$ Currently, CEA is the gold-standard treatment modality for severe CAS. ${ }^{[3]}$ One of the controversial issues regarding CEA is the closure technique of arteriotomy after CEA. In primary closure, 1 to $36 \%$ restenosis ratio requires the development of alternative methods and, therefore, the European Society for Vascular Surgery (ESVS) guidelines recommend patch closure after CEA. ${ }^{[4-6]}$ This proposal is based on the Cochrane Collaboration in 2009, which was updated in 2011, and dates back approximately to 20 years. ${ }^{[7,8]}$ According to the existing data, patch angioplasty closure reduces the risk of perioperative stroke, restenosis, and long-term ipsilateral ischemic stroke. ${ }^{[7,8]}$ It has been reported that the rate of postoperative stroke and death reduce and, with the advance of technology and modern practices, 3 to $7 \% \cdot{ }^{[4,9-12]}$ In recent studies including the Carotid Revascularization Endarterectomy versus Stenting Trial (CREST) and
National Surgical Quality Improvement Program (NSQIP) data, there were no significant differences in the rates of postoperative restenosis, stroke, and death between these two methods. ${ }^{[11,13-15]}$

In the current study, we aimed to evaluate perioperative and long-term results of CEA in terms of primary closure and patch techniques.

\section{PATIENTS AND METHODS}

This retrospective study included a total of 289 patients (145 males, 144 females; mean age $64.9 \pm 3.85$ years; range, 53 to 84 years) who underwent elective CEA in our clinic between January 2014 and January 2019. The patients were divided into two

Corresponding author: Aykut Şahin, MD. Eskişehir Osmangazi Üniversitesi Tıp Fakültesi, Kalp ve Damar Cerrahisi Anabilim Dalı, 26040 Meşelik, Eskişehir, Türkiye. Tel: +90222 - 23929 79 / 3400 e-mail: draykutsahin@gmail.com

\section{Citation:}

Şahin A, Dernek S. Is primary closure still a reliable technique in carotid endarterectomy? Cardiovasc Surg Int 2020;7(3):157-162. 
groups as Group $1(n=62)$ receiving patch closure and Group $2(\mathrm{n}=227)$ receiving primary closure. Patients who received a concurrent operation with CEA, such as neck procedures or open heart surgery were excluded from the study. Baseline demographic and clinical characteristics and peri- and postoperative complications were recorded. If there was severe CAS (>70\%) in symptomatic or asymptomatic patients, the patients were evaluated by the Neurology and Cardiovascular Surgery Council, and the operation decision was taken. A written informed consent was obtained from each patient. The study protocol was approved by the Eskişehir Osmangazi University Faculty of Medicine Ethics Committee (No. 2019-319). The study was conducted in accordance with the principles of the Declaration of Helsinki.

\section{Surgical procedure}

All patients were operated under general anesthesia and their systolic arterial blood pressures were invasively monitored and kept at a level of 140 to $160 \mathrm{mmHg}$. A patch was used where the internal carotid artery (ICA) diameter was less than $5 \mathrm{~mm}$ and/or if the stenosis extended to the distal of ICA. None of the patients needed a shunt. Under near-infrared spectroscopy (NIRS), the carotid arteries were exposed and suspended. Before clamping the arteries, $100 \mathrm{IU} / \mathrm{kg}$ heparin was administered intravenously. A longitudinal incision was made to extend to the ICA, and the plaques within the ICA, external carotid artery (ECA), and common carotid artery (CCA) were removed with a dissector.

After the full opening was achieved in Group 1, the saphenous vein was prepared and trimmed as a patch. This patch was used for closure of the carotid incision. On the other hand, in Group 2, the incision was closed with a continuous suturing method using 6/0 propylene. A mini-drain was placed in all patients, and the subcutaneous areas and skin were closed with an absorbable polyglactin stitches. All the patients were extubated at the operating room. The patients were, then, taken to the intensive care unit and followed with an appropriate dose of heparin infusion after arterial blood pressure regulation.

The patients received combined antiaggregant medical therapy (acetylsalicylic acid $100 \mathrm{mg}$ and clopidogrel $75 \mathrm{mg}$ ) as of the postoperative Day 1 .
If the patients needed an anticoagulant therapy due to atrial fibrillation, previous mechanical heart valve replacement, or previous deep vein thrombosis, they were prescribed acetylsalicylic acid $100 \mathrm{mg}$ and warfarin at appropriate doses (international normalized ratio [INR]: 2,5-3). The patients were transferred to the ward in the first postoperative day provided that their general condition was stable.

All patients were followed for one year. Control Doppler ultrasonography was performed at one, six, and 12 months after surgery for all patients. If there was stenosis over $50 \%$ on Doppler ultrasonography, computed tomography angiography (CTA) was performed. The diagnosis of restenosis was made based on CTA results.

\section{Statistical analysis}

Statistical analysis was performed using the PSPP version 1.2.0 software (Free Software Foundation, Inc., MA, USA). Descriptive data were expressed in mean \pm standard deviation (SD), median (min-max) or number and frequency. The Pearson chi-square (including continuity correction) and Fisher's exact test were used to compare categorical data between the groups. A $p$ value of $<0.05$ was considered statistically significant.

\section{RESULTS}

Baseline demographic and clinical characteristics of the patients are summarized in Table 1 . Of a total of 289 patients who underwent CEA, primary closure was performed in 227 patients and patch angioplasty in 62 patients. There was no statistically significant difference in the baseline demographic data between the patient groups. However, the mean cross-clamp time was $30.4 \pm 3.8 \mathrm{~min}$ in Group 1 and $20.7 \pm 2.5 \mathrm{~min}$ in Group $2(\mathrm{p}<0.001)$, indicating significantly shorter time in the primary closure than the patch closure technique.

A total of 11 patients underwent postoperative neck exploration due to surgical site hematoma, $8.1 \%(n=5)$ in Group 1 and 2.6\% ( $n=6)$ in Group 2 $(\mathrm{p}=0.048)$. The incidence of surgical site hematoma was statistically higher in Group 1. Immediate-term stroke rate after surgery was $1.6 \%(n=1)$ in Group 1 and $3.1 \%(n=7)$ in Group 2. Except for the early postoperative period, stroke was seen at one week $(1.3 \%, \mathrm{n}=3)$ and one year $(2.6 \%, \mathrm{n}=6)$ in only Group 2. There was no statistically significant 


\begin{tabular}{|c|c|c|c|c|c|c|c|}
\hline \multirow[b]{3}{*}{ Variable } & \multicolumn{6}{|c|}{$\begin{array}{l}\text { Table } 1 \\
\text { d clinical characteristics of patients }\end{array}$} & \multirow[b]{3}{*}{$p$} \\
\hline & \multicolumn{3}{|c|}{ Group $1(n=62)$} & \multicolumn{3}{|c|}{ Group $2(n=227)$} & \\
\hline & $\mathrm{n}$ & $\%$ & Mean \pm SD & $\mathrm{n}$ & $\%$ & Mean \pm SD & \\
\hline Age (year) & & & $64.2 \pm 3.5$ & & & $65.1 \pm 3.9$ & $0.087^{*}$ \\
\hline \multicolumn{8}{|l|}{ Sex } \\
\hline Male & 26 & 41.9 & & 119 & 52.4 & & $0.143 \dagger$ \\
\hline Family history & 4 & 6.5 & & 12 & 5.3 & & $0.966 \ddagger$ \\
\hline Smoking & 28 & 45.2 & & 110 & 48.5 & & $0.645 \dagger$ \\
\hline Diabetes mellitus & 10 & 16.1 & & 30 & 13.2 & & $0.556 \dagger$ \\
\hline Systemic hypertension & 17 & 27.4 & & 77 & 33.9 & & $0.333 \dagger$ \\
\hline Coronary artery disease & 6 & 9.7 & & 23 & 10.1 & & $0.916 \dagger$ \\
\hline Peripheral artery disease & 6 & 9.7 & & 16 & 7 & & $0.489 \dagger$ \\
\hline Cerebrovascular accident & 13 & 21 & & 51 & 22.5 & & $0.801 \dagger$ \\
\hline Bilateral carotid endarterectomy & 8 & 12.9 & & 32 & 14.1 & & $0.809 \dagger$ \\
\hline Clamp time (min) & & & $30.4 \pm 3.8$ & & & $20.7 \pm 2.5$ & $<0.001^{*}$ \\
\hline
\end{tabular}

difference in the stroke rate between the groups. The rate of acute myocardial infarction (AMI) was $3.2 \%$ in Group 1 and $0.9 \%$ in Group 2. The mortality rate was $0.4 \%$ in Group 2, while there was no mortality in Group 1. In addition, there was no significant difference in the complication rate, except for hematoma, between the groups. The postoperative results are presented in Table 2.

\section{DISCUSSION}

To date, the CEA studies have provided highly controversial results in terms of post-CEA closure techniques. The general view is that the patch closure method minimizes the risk of perioperative and long-term stroke and restenosis, compared to the primary closure method; however, the existence of

\begin{tabular}{|c|c|c|c|c|c|}
\hline \multicolumn{6}{|c|}{$\begin{array}{c}\text { Table } 2 \\
\text { Postoperative outcomes }\end{array}$} \\
\hline & \multicolumn{2}{|c|}{ Group $1(n=62)$} & \multicolumn{2}{|c|}{ Group $2(\mathrm{n}=227)$} & \multirow[b]{2}{*}{$p$} \\
\hline & $\mathrm{n}$ & $\%$ & $\mathrm{n}$ & $\%$ & \\
\hline Acute myocardial infarction & 2 & 3.2 & 2 & 0.9 & $0.431 \dagger$ \\
\hline Hematoma & 5 & 8.1 & 6 & 2.6 & $0.048^{*}$ \\
\hline Stroke (immediate-term) & 1 & 1.6 & 7 & 3.1 & $0.850 \ddagger$ \\
\hline Stroke ( $1^{\text {st }}$ week $)$ & 0 & 0 & 3 & 1.3 & $0.839 \ddagger$ \\
\hline Stroke $\left(1^{\text {st }}\right.$ year $)$ & 0 & 0 & 6 & 2.6 & $0.429 \neq$ \\
\hline TIA (immediate-term) & 3 & 4.8 & 5 & 2.2 & $0.494 \ddagger$ \\
\hline Restenosis (50-70\%) & 3 & 4.8 & 5 & 2.2 & $0.494 \ddagger$ \\
\hline Restenosis ( $\geq 70 \%) \rrbracket$ & 0 & 0 & 3 & 1.3 & $0.839 \ddagger$ \\
\hline Mortality $\Phi$ & 0 & 0 & 1 & 0.4 & $1.0 \neq$ \\
\hline
\end{tabular}


controversial results requires more studies to support these findings. ${ }^{[7,8,16-18]}$ There is still no consensus among the surgeons about the closure technique and, therefore, each surgeon decides on the closure technique based on his or her own experience. In the present study, we found no statistically significant difference in the perioperative results, except for hematoma, between the two groups.

In previous studies, the effects of closure techniques in CEA on complications developed after surgery were studied. In a meta-analysis conducted in 2,157 patients, the patch closure technique was associated with a significant reduction in perioperative ipsilateral stroke and ICA thrombosis within 30 days. ${ }^{[19]}$ Besides, in the long-term, late ipsilateral stroke and ICA restenosis rates reduced in patients undergoing patch closure technique. However, there was no significant difference between the primary and patch closure techniques in terms of perioperative and stroke-related mortality. Similarly, another study reported lower restenosis rates compared to primary closure after patch procedure. ${ }^{[20]}$ In addition, patients undergoing patch closure had a lower rate of restenosis within two years after CEA. ${ }^{[21]}$ In this study, restenosis rates were slightly higher in Group 2, although not statistically significant. This result can be attributed to the patient selection criteria used in the study.

In the first Cochrane review published in 2009 and which was updated in 2011, there was no significant difference between the two closure methods in the perioperative period; however, the patch closure method was reported to reduce stroke and restenosis rates in the long-term. ${ }^{[7,22]}$ In a study in which the patch closure method was riskier than primary closure was emphasized, patients who received patch closure (12.9\%) had an incidence of recurrent CAS compared to those with primary closure (1.7\%). ${ }^{[23]}$ In this study, the authors used venous patch material and, in case of using a saphenous vein, it did not show any superiority over primary closure in the long-term of five years. However, many other studies suggested that there was no significant difference between the two closure methods. In one of these studies, neither methods affected the occlusion or stroke rates. ${ }^{[23]}$

On the other hand, the primary closure method has several advantages compared to the patch closure method, including low risk of infection, fewer complications, and shorter operation and arteriotomy time. ${ }^{[13,14,18]}$ Previous retrospective studies have shown that closure techniques do not affect perioperative and long-term postoperative results. In a study conducted using the American College of Surgeons (ACS) NSQIP database, closure techniques for CEA were not found to be associated with complications. On the contrary, one or more high-risk features such as preoperative stroke, age above 80 years, and active smoking were found to be predictors of 30-day postoperative stroke or death after CEA in patients having these risks. ${ }^{[14]}$ In a very recent study conducted in South Korea, no significant difference in restenosis rates was observed in the perioperative period and long-term after patch and primary closure techniques in 435 patients. ${ }^{[2]}$ In another study, there was no statistically significant difference in the restenosis rate in the mid-term between the patch closure and primary closure techniques. ${ }^{[25]}$ This finding is also consistent with our study results. Some urgent CEAs were performed with primary closure for short cross-clamp time of carotid arteries. ${ }^{[26]}$ Also, in our study, primary closure technique decreased clamping time, although there was no significant difference in the stroke rates in early- and mid-term.

Doppler ultrasonography can be useful in following patients after surgery for restenosis and preoperative risks. ${ }^{[27]}$ In our study, we followed patients with Doppler ultrasonography after surgery. If there was stenosis over $50 \%$ on Doppler ultrasonography, we used CTA for these patients. Furthermore, although combined antiaggregant and anticoagulant therapy was administered in a study, ${ }^{[28]}$ in our study, medical treatment was chosen for each case individually.

Nonetheless, there are some limitations to this study. Its retrospective and single-center design are the main limitations which preclude the generalization of the results. In addition, common opinions in choosing a closure technique for surgeons working in a single center may lead to a biased selection. Also, as perioperative data were not included in our study, postoperative results were further elaborated. Additionally, the duration of follow-up was relatively short (one year) and, thus, long-term follow-up is required for further evaluation and recommendation. Also, if the ICA diameter was below $5 \mathrm{~mm}$, primary closure technique was not preferred, indicating a significant difference in the anatomical structure of the ICA between the two groups. We believe 
that further large-scale, long-term, prospective, randomized studies would provide more robust data about the primary closure technique.

In conclusion, there was no significant difference between the primary and patch closure techniques in terms of AMI, short- and long-term stroke, transient ischemic attack, and long-term restenosis and mortality rates. Our study results suggest that the application of patch or primary closure techniques during CEA has no significant superiority to each other in the early- and mid-term. In eligible cases and in whom the ICA diameter is over $5 \mathrm{~mm}$, primary closure can be performed safely.

\section{Declaration of conflicting interests}

The authors declared no conflicts of interest with respect to the authorship and/or publication of this article.

\section{Funding}

The authors received no financial support for the research and/or authorship of this article.

\section{REFERENCES}

1. Goldstein LB, Bushnell CD, Adams RJ, Appel LJ, Braun LT, Chaturvedi $S$, et al. Guidelines for the primary prevention of stroke: a guideline for healthcare professionals from the American Heart Association/American Stroke Association. Stroke 2011;42:517-84.

2. Naylor AR, Sayers RD, McCarthy MJ, Bown MJ, Nasim A, Dennis MJ, et al. Closing the loop: a 21-year audit of strategies for preventing stroke and death following carotid endarterectomy. Eur J Vasc Endovasc Surg 2013;46:161-70.

3. Hıdıroğlu M, Çetin L, Kunt A, Karakişi O, Küçüker A, Şener E. Karotis arter hastalıklarında karotis endarterektomi erken sonuçları. Türk Gögüs Kalp Damar Cer Derg 2010;18:190-5.

4. Arquizan C, Trinquart L, Touboul PJ, Long A, Feasson S, Terriat $\mathrm{B}$, et al. Restenosis is more frequent after carotid stenting than after endarterectomy: the EVA-3S study. Stroke 2011;42:1015-20.

5. Bekelis K, Moses Z, Missios S, Desai A, Labropoulos N. Indications for treatment of recurrent carotid stenosis. Br J Surg 2013;100:440-7.

6. Lattimer CR, Burnand KG. Recurrent carotid stenosis after carotid endarterectomy. Br J Surg 1997;84:1206-19.

7. Rerkasem K, Rothwell PM. Patch angioplasty versus primary closure for carotid endarterectomy. Cochrane Database Syst Rev 2009;2009:CD000160.

8. Rerkasem K, Rothwell PM. Systematic review of randomized controlled trials of patch angioplasty versus primary closure and different types of patch materials during carotid endarterectomy. Asian J Surg 2011;34:32-40.
9. Demirel S, Attigah N, Bruijnen H, Ringleb P, Eckstein $\mathrm{HH}$, Fraedrich G, et al. Multicenter experience on eversion versus conventional carotid endarterectomy in symptomatic carotid artery stenosis: observations from the StentProtected Angioplasty Versus Carotid Endarterectomy (SPACE-1) trial. Stroke 2012;43:1865-71.

10. Gurm HS, Yadav JS, Fayad P, Katzen BT, Mishkel GJ, Bajwa TK, et al. Long-term results of carotid stenting versus endarterectomy in high-risk patients. N Engl J Med 2008;358:1572-9.

11. Lal BK, Beach KW, Roubin GS, Lutsep HL, Moore WS, Malas MB, et al. Restenosis after carotid artery stenting and endarterectomy: a secondary analysis of CREST, a randomised controlled trial. Lancet Neurol 2012;11:755-63.

12. Malas M, Glebova NO, Hughes SE, Voeks JH, Qazi U, Moore WS, et al. Effect of patching on reducing restenosis in the carotid revascularization endarterectomy versus stenting trial. Stroke 2015;46:757-61.

13. Al-Rawi PG, Turner CL, Waran V, Ng I, Kirkpatrick PJ. A randomized trial of synthetic patch versus direct primary closure in carotid endarterectomy. Neurosurgery 2006;59:822-8.

14. Bennett KM, Scarborough JE, Shortell CK. Predictors of 30-day postoperative stroke or death after carotid endarterectomy using the 2012 carotid endarterectomytargeted American College of Surgeons National Surgical Quality Improvement Program database. J Vasc Surg 2015;61:103-11.

15. Tan TW, Weyman AK, Barkhordarian S, Patterson RB. Single center experience with modified eversion carotid endarterectomy. Ann Vasc Surg 2011;25:87-93.

16. Babu MA, Meissner I, Meyer FB. The durability of carotid endarterectomy: long-term results for restenosis and stroke. Neurosurgery 2013;72:835-8.

17. Harrison GJ, Brennan JA, Naik JB, Vallabhaneni SR, Fisher RK. Patch variability following carotid endarterectomy: a survey of Great Britain and Ireland. Ann R Coll Surg Engl 2012;94:411-5.

18. Kumar S, Lombardi JV, Alexander JB, Carabasi RA, Carpenter JP, Trani JL. Modified eversion carotid endarterectomy. Ann Vasc Surg 2013;27:178-85.

19. Naylor AR, Ricco JB, de Borst GJ, Debus S, de Haro J, Halliday A, et al. Editor's Choice - Management of Atherosclerotic Carotid and Vertebral Artery Disease: 2017 Clinical Practice Guidelines of the European Society for Vascular Surgery (ESVS). Eur J Vasc Endovasc Surg 2018;55:3-81.

20. Mannheim D, Weller B, Vahadim E, Karmeli R. Carotid endarterectomy with a polyurethane patch versus primary closure: a prospective randomized study. J Vasc Surg 2005;41:403-7.

21. Chechik O, Goldstein Y, Behrbalk E, Kaufman E, Rabinovich Y. Blood loss and complications following carotid endarterectomy in patients treated with clopidogrel. Vascular 2012;20:193-7. 
22. Bond R, Rerkasem K, AbuRahma AF, Naylor AR, Rothwell PM. Patch angioplasty versus primary closure for carotid endarterectomy. Cochrane Database Syst Rev 2004;2:CD000160.

23. Clagett GP, Patterson CB, Fisher DF Jr, Fry RE, Eidt JF, Humble TH, et al. Vein patch versus primary closure for carotid endarterectomy. A randomized prospective study in a selected group of patients. J Vasc Surg 1989;9:213-23.

24. Chung BH, Heo SH, Park YJ, Kim YW, Woo SY, Kim DI. Comparative Analysis Using Propensity Score Matching Analysis: Primary Closure versus Patch Angioplasty During Carotid Endarterectomy. Ann Vasc Surg 2020;62:166-72.

25. İyigün T, Kyaruzi M, Timur B, İyigün M, Aydın Ü. Our midterm restenosis results using patch angioplasty closure versus primary closure in patients undergoing carotid endarterectomy: A comparative study. Turk J Vasc Surg 2019;28:19-23.

26. Ertugay S, Eraslan C, Posacıoglu H. Intraplaque hemorrhage causing recurrent stroke treated by carotid endarterectomy. Cardiovasc Surg Int 2019;6:38-40.

27. Tanrıverdi O, Aşkın L, Serçelik A. Association between non-dipping status and carotid intima-media thickness in patients with elevated blood pressure category. Cardiovascular Surgery and Interventions 2020;7:76-83.

28. Erdinç İ, Melis Öztaş D, Demir İ, Uğurlucan M, Tankut Akay H. Medical treatment experience following carotid endarterectomy in atrial fibrillation presenting with carotid artery stenosis. Turk J Vasc Surg 2018;27:85-90. 